\title{
Desempenho de matriz leiteira mestiça semi-confinada alimentada com dieta à base de farelo de algodão
}

\author{
Performance of mixed matrix semi-confined milk fed diet of cottonseed \\ meal
}

\section{Helen Ramalho de Farias Pinto ${ }^{1 \cdot 2 * *}$, Marcos Roberto Cavalcante' Helen Karla Ramalho de Farias Pinto ${ }^{1}$, João de Deus Nunes Neto ${ }^{1}$, Carlos Antônio Cabral dos Santos', Silvana Silva', Diógenes Montenegro Gomes de Brito Silva', Suelene Alves Marinho Cavalcante $^{2}$}

${ }^{1}$ Universidade Federal da Paraíba, Campus Universitário, João Pessoa-PB (CEP 58051-900).*E-mail: helenrpinto@gmail.com.

${ }^{2}$ Instituto Brasileiro do Meio Ambiente e dos Recursos Naturais Renováveis, Superinntendência na Paraíba. Av. Dom Pedro II, 3284, João Pessoa-PB (CEP 58040-915).

\begin{abstract}
Resumo. O objetivo deste trabalho foi avaliar os desempenhos dos bovinos (matrizes mestiças leiteiras) semi-confinados alimentados com dietas à base de farelo de algodão, farelo (raspa) de mandioca, farelo de trigo, farelo de milho, tendo como material volumoso silagem e palma forrageira in natura e suplemento mineral sal mineralizado. O experimento teve duração de 90 dias, sendo 15 dias de pré-análise. A mistura alimentícia administrada foi elaborada para nutrir animal ruminante (matriz em lactação). A formulação alimentar (mistura $\mathrm{n}^{\mathrm{0}}$ 4) destinada às matrizes foi administrada com auxílio de micronutrientes, tendo obtido sucesso na ingesta. A composição alimentar foi mantida numa proporção volumoso : concentrado, de 63:37, com aproximadamente, $20 \%$ de proteínas. Na avaliação final do experimento houve aumento de $20 \%$ na produção de leite e melhorias nos desempenhos físicos das carcaças das matrizes.
\end{abstract}

Palavras-chave: Gestão ambiental rural; farelo de algodão; semiconfinamento; matriz mestiça leiteira.

\begin{abstract}
The aim of this study was to evaluate the performances of cattle (crossbred dairy matrices) semi-confined fed diets based on cottonseed meal, soybean meal (zest) of cassava, wheat bran, corn bran, with the bulky material silage and forage cactus in natura and mineral supplement mineral salt. The experiment lasted 90 days with 15 days of pre-analysis. The mixture was administered food prepared to feed ruminant animal (lactating mother). The feed formulation (mixture \# 4) for the matrices was administered with the aid of micronutrients, having succeeded in intake. The feed composition was held in forage: concentrate ratio of $63: 37$ with about $20 \%$ protein. In the final evaluation of the experiment there was a $20 \%$ increase in milk production and improvements in physical performance of the carcasses of the matrices.
\end{abstract}

Keyword: Rural environmental management; cottonseed meal; bran semiconfinement; mixed matrix.

\section{Introdução}

Os farelos proteicos naturais como os de algodão, são eficientes na suplemen-
Recebido: 10/09/2014

Aceito: 30/09/2014

Publicado: 20/11/2014

Acesso aberto.

Artigo completo. 
protéico (NNP), como a ureia (Swingle et al., 1977).

A eficiência da utilização de nitrogênio ou amônia pelos microrganismos do rúmen é maior quando a ureia é utilizada em dietas com baixo nível de nitrogênio, elevados níveis de energia, minerais e outros compostos que aumentam a atividade microbiana (Campos e Rodrigues, 1985). Das fontes de energia disponíveis, o amido é o mais satisfatório, por ser fermentado à taxa relativamente constante (Maynard et al., 1979). O uso de ureia pelos ruminantes é limitado em virtude de sua baixa aceitabilidade e sua toxicidade (Chalupa, 1968) agravada pela sua elevada solubilidade no rúmen, o que a transforma muito rapidamente em amônia (Owens et al., 1980; Daugherty e Church, 1982), devido à ação da enzima urease produzida pelos microrganismos ruminantes (Owens e Zinn, 1988; Reynolds, 1992). O produto resultante da extrusão do amido com a ureia, conhecido como amireia, pode acarretar efeitos positivos na utilização da ureia para ruminantes (Helmer, 1970).

O objetivo desse trabalho foi avaliar o desempenho de bovinos (matriz leiteira) semi-confinados, alimentados com mistura protéica elaborada com coprodutos da obtenção de biocombustíveis da produção de biodiesel de algodão (farelo de algodão) e etanol (farelo de mandioca); alguns ingredientes, tais como, rolão (restos de culturas desidratadas, como palhas de milho secas, feijão, capim seco, etc.), farelo de milho, farelo de trigo e material volumoso (silagem e palma forrageira), ureia e outros micronutrientes.

$\mathrm{O}$ estudo foi realizado com a finalidade de evitar desperdícios de coprodutos resultantes das obtenções de biocombustíveis, bem como, verificar as aceitabilidades das preparações alimentícias elaboradas com os coprodutos desta produção, promovendo a sustentabilidade ambiental e o aumento dos desempenhos físicos das carcaças dos animais.

\section{Material e Métodos}

O experimento foi realizado durante o período de janeiro a março de 2014, sendo o período pré-experimental de 15 dias, que serviu para a adaptação dos animais a esta nova condição realizada numa fazenda de porte médio, localizada na mesorregião do Agreste Paraibano, Município de Aroeiras. Os animais ruminantes (vacas leiteiras, mestiças), em número de seis foram semi-confinados em instalações cobertas de alvenaria, com seis subdivisões para dois animais em cada baia, munidas de cochos e bebedouro.

Os animais bovinos (matrizes mestiças leiteiras), com três anos de idade, apresentavam peso aproximado de 450 $\mathrm{kg} /$ cabeça/PV (peso vivo). Esees animais foram colocados aleatoriamente nas subdivisões em grupo de dois animais por ambiente, para o período de pré-experimento no qual foram realizadas algumas adaptações dos animais ao local, manejo e a incorporação da alimentação da nova dieta.

O semi-confinamento de engorda com as matrizes lactantes foi realizado para a avaliação dos desempenhos físicos das carcaças. Nessa dieta foi utilizado silagem de milho e palma forrageira in natura, como material volumoso e como concentrados os ingredientes farelo de algodão, farelo de mandioca, farelo de trigo e farelo de milho. A esta mistura foram adicionados sal mineralizado, ureia e alguns micronutrientes, tendo sido servidos em cochos apropriados.

A produção do material volumoso da composição alimentícia animal, conhecido como silagem, foi obtida na fazenda dos agropecuaristas colaboradores da região do Agreste Paraibano, tendo sido composto em silos trincheira e de superfície. Diariamente, nos horários de alimentação animal, foram administradas a mistura $\mathrm{n}^{0} 4$ de Pinto (2014) aos ruminantes no cocho, composta de silagem de milho, palma forrageira in natura triturada e o material concentrado elaborado, disponível na proporção de farelo de algodão (40\%), farelo de trigo (30\%), farelo de mandioca (20\%) e farelo de milho (5\%). A composição química dos ingredientes desta mistura alimentícia encontra-se na Tabela 1.

\section{Resultados e Discussão}

Segundo Orskov (1982), conhecer a natureza protéica da dieta é importante para minimizar os desempenhos físicos das carcaças dos ruminantes. A fonte de nitrogênio que é utilizada pelos microrganismos do 
Tabela 1. Composição química dos ingredientes da mistura alimentícia.

\begin{tabular}{lccc}
\hline Ingredientes & $\begin{array}{c}\text { Matéria seca } \\
(\mathbf{\%})\end{array}$ & $\begin{array}{c}\text { Proténa bruta } \\
\mathbf{( \% )}\end{array}$ & $\begin{array}{c}\text { Energia metabolizada } \\
\text { calculada (Mcal/MS) }\end{array}$ \\
\hline Farelo de algodão & 93,0 & 44,1 & $2,82^{1}$ \\
Farelo de milho & 41,0 & 4,0 & $1,59^{1}$ \\
Silagem milho & 32,6 & 8,8 & $2,39^{1}$ \\
Farelo de trigo & 89,0 & 17,1 & $2,53^{1}$ \\
Farelo de mandioca & 87,6 & 2,47 & $2,39^{2}$ \\
\hline
\end{tabular}

${ }^{1}$ NRC (1989; 1996). ${ }^{2}$ Rostagno (2011).

rúmen para a síntese de proteína é composta tanto da proteína dietética, como do nitrogênio reciclado no rúmen. Em muitas situações alimentares, o nitrogênio que atinge o intestino é, em grande parte, de origem microbiana, portanto, o crescimento microbiano tem grande influência na utilização da proteína pelos ruminantes. De acordo com NRC (1996), a quantidade de proteína degradável no rúmen é de $850 \mathrm{~g} /$ cabeça/dia, para animal Nelore de 300 a $450 \mathrm{~kg}$ de peso vivo. Da mesma forma, comparativamente as misturas alimentícias com farelo de algodão satisfazem sem excessos o requerimento em proteína degradável.

Os índices de conversão alimentar encontrados na literatura (e.g., Seixas et al., 1999; Fernandes et al., 2009; Alves et al., 2010) são distintos em razão das demais variáveis nos ensaios, tais como idade dos animais, período experimental, raça, sexo e alimentação adotada para os testes.

Mesmo não podendo aferir a evolução corporal dos animais através do peso vivo diário do plantel, impossibilitando a obtenção dos resultados de conversão alimentar, ingestão de matéria seca, ingestão de proteína bruta e conversão protéica no período total de semi-confinamento das matrizes leiteiras mestiças, foi possível avaliar o aumento da produção de leite em $20 \%$, bem como, a melhoria dos desempenhos físicos das carcaças das matrizes.

\section{Considerações finais}

De acordo com os dados obtidos nesse estudo e na literatura especializada (e.g., Seixas et al., 1999; Fernandes et al., 2009; Alves et al., 2010), pode-se concluir que o farelo de algodão tem alto potencial para substituir o farelo de soja na alimentação de gado bovino. Entretanto, do mesmo modo que observou Seixas et al. (1999), seu uso depende das variações de mercado.

Novas pesquisas devem ser realizadas no intuito de avaliar a evolução do peso vivo diário dos animais, para acompanhar o percentual de ganho de peso vivo por animal.

\section{Referências}

Alves, A. F.; Zervoudakis, J. T.; HatamotoZervoudakis, L. K.; Cabral, L. S.; Leonel, F. P.; Paula, N. F. Substituição do farelo de soja por farelo de algodão de alta energia em dietas para vacas leiteiras em produção: consumo, digestibilidade dos nutrientes, balanço de nitrogênio e produção leiteira. R. Bras. Zootec., v. 39, p.532-540, 2010.

Campos, O. F.; Rodrigues, A. A. Ureia para bovino em crescimento. Embrapa/CNPGL, 1985.

Chalupa, W. Problems in feed urea to ruminants. J. Anim. Sci., v. 27, p. 207, 1968.

Daugherty, D. A.; Church, D. C. In vivo and In vitro evaluation of feather and hair meals in combination with urea for ruminants. J. Anim. Sci., v. 54, p. 345, 1982.

Fernandes, J. J. R.; Pires, A. V.; Oliveira Jr., R. C.; Santos, F. A. P.; Susin, I.; Carvalho, E. R. Farelo de soja em substituição à ureia em dietas para bovinos de corte em crescimento. Ciência Animal Brasileira, v. 10, p. 373-378, 2009.

Helmer, L. G. Feed processing - Effect of an expansion-processed mixture of grain and urea (Starea) on nitrogen utilization in vitro. J. Dairy Sci., v. 53, p. 330, 1970.

Maynard, L. A.; Loosli, J. K., Hintz, H. F.; Warner, R. G. Animal nutrition. 7. ed. New York: McGraw-Hill, 1979.

NRC - National Research Council. Nutrient requirements of dairy cattle. Washington: National Academy of Science, 1989.

NRC - National Research Council. Nutrient requirements of dairy cattle. Washington: National Academy of Science, 1996. 
Orskov, E. R. Protein nutrition in ruminants. London: Academic Press, 1982.

Owens, F. N.; Bergen, W. G. Nitrogen metabolism of ruminant animals: Historical perspective, current understanding, and future implications. J. Anim. Sci., v. 57, p. 498, 1983.

Owens, F. N.; Zinn, R. Metabolismo de la proteina en lós ruminants. In: Church, C. D. El ruminante: fisiología digestiva y nutrición. Zaragoza: Acribia, 1988.

Owens, F. N.; Lusby, K. S.; Mizwicki, K.; Forero, O. Slow ammonia release from urea: rumen and metabolism studies. J. Anim. Sci., v. 50, p. 527-31, 1980.

Pinto, H. R. F. Estudo dos coprodutos da produção de biocombustível (etanol e biodiesel), para obtenção de insumo alimentar animal. João Pessoa: PPGEM/CT/UFPB, 2014. (Tese de doutorado).
Reynolds, C. K. Metabolism of nitrogenous compounds by ruminants liver. J. Nutr., v. 122, p. 1251-1255, 1992.

Rostagno, H. S. Tabelas brasileiras para aves e suínos: composição de alimentos e existências nutricionais. 3. ed. Viçosa: UFV, Departamento de Zootecnia, 2011.

Seixas, J. R. C.; Ezequiel, J. M. B.; Araújo, W. A.; Resende, F. D.; Martins Junior, A.; Kronka, S. N.; Silva, L. D. F.; Dourado, J. B.; Soares, W. V. B. Desempenho de bovinos confinados alimentados com dietas à base de farelo de algodão, ureia ou amireia. Rev. bras. zootec., v. 28, p. 432-438, 1999.

Swingle, R. S.; Araiza, A.; Urias, A. R. Nitrogen utilization by lambs fed wheat straw alone or with supplements containing dried poutry waste, cotton seed meal or urea. J. Anim. Sci., v. 45, p. 1435-1441, 1977. 